\title{
ORIGINAL ARTICLE Phospholipase D (PLD) drives cell invasion, tumor growth and metastasis in a human breast cancer xenograph model
}

\author{
KM Henkels ${ }^{1}$, GP Boivin ${ }^{2,3}$, ES Dudley ${ }^{2}$, SJ Berberich ${ }^{1}$ and J Gomez-Cambronero ${ }^{1}$
}

Breast cancer is one of the most common malignancies in human females in the world. One protein that has elevated enzymatic lipase activity in breast cancers in vitro is phospholipase D (PLD), which is also involved in cell migration. We demonstrate that the PLD2 isoform, which was analyzed directly in the tumors, is crucial for cell invasion that contributes critically to the growth and development of breast tumors and lung metastases in vivo. We used three complementary strategies in a SCID mouse model and also addressed the underlying molecular mechanism. First, the PLD2 gene was silenced in highly metastatic, aggressive breast cancer cells (MDA-MB-231) with lentivirus-based short hairpin RNA, which were xenotransplanted in SCID mice. The resulting mouse primary mammary tumors were reduced in size $(65 \%, P<0.05)$ and their onset delayed when compared with control tumors. Second, we stably overexpressed PLD2 in low-invasive breast cancer cells (MCF-7) with a biscistronic MIEG retroviral vector and observed that these cells were converted into a highly aggressive phenotype, as primary tumors that formed following xenotransplantation were larger, grew faster and developed lung metastases more readily. Third, we implanted osmotic pumps into SCID xenotransplanted mice that delivered two different small-molecule inhibitors of PLD activity (5-fluoro-2-indolyl deschlorohalopemide and $\mathrm{N}$-[2-(4-oxo-1-phenyl-1,3,8-triazaspiro[4,5]dec-8-yl)ethyl]-2-naphthalenecarboxamide). These inhibitors led to significant $(>70 \%, P<0.05)$ inhibition of primary tumor growth, metastatic axillary tumors and lung metastases. In order to define the underlying mechanism, we determined that the machinery of PLD-induced cell invasion is mediated by phosphatidic acid, Wiscott-Aldrich Syndrome protein, growth receptor-bound protein 2 and Rac2 signaling events that ultimately affect actin polymerization and cell invasion. In summary, this study shows for the first time that PLD2 has a central role in the development, metastasis and level of aggressiveness of breast cancer, raising the possibility that PLD2 could be used as a new therapeutic target.

Oncogene (2013) 32, 5551-5562; doi:10.1038/onc.2013.207; published online 10 June 2013

Keywords: cell signaling; human breast cancer; PLD; cell invasion and metastasis; SCID mice; xenotransplant

\section{INTRODUCTION}

Breast cancer is globally the most common malignancy affecting greater than one million human females per year in 145 countries surveyed. ${ }^{1,2}$ Breast cancer metastasis, which is the primary cause of death in patients, is a complex process that involves cell proliferation, invasion through basement membrane and vessel walls, diapedesis into capillaries or lymphatic vessels and further establishment of new colonies in other tissues. ${ }^{3-5}$ Cell invasion and metastasis need the interaction of a developmental regulatory program, called epithelial-mesenchymal transition, for transformed epithelial cells to acquire several malignant attributes that enable them to systematically invade adjacent tissues. ${ }^{6}$ Matrix metalloproteinase secretion, which requires the full function of the actin-based motility machinery of the cell, is involved in metastasis and is mediated by phospholipase D (PLD), which contributes to in vitro tumor cell invasion. ${ }^{7-12}$

Phosphatidic acid (PA)-dependent PLD is required for actin polymerization and ruffle formation, chemotaxis and phagocytosis and elevated PLD activity has been found in colorectal, renal, gastric and breast cancers, as well as melanoma. ${ }^{13-22}$ PLD confers rapamycin resistance and survival signals in human cancer cells with activated H-Ras or K-Ras. ${ }^{19,23}$ There is also a requirement for normal PLD catalytic activity in H-RasV12-induced transformation of normal Rat-2 fibroblasts. ${ }^{24}$ Elevation of either PLD or especially the PLD2 isoform has the potential to transform both murine and rat fibroblasts. ${ }^{25-27}$ The potential exists for stimulation of PLD activity to directly contribute to cell proliferation, which further compounds the formation of a fully malignant phenotype. ${ }^{28-30}$ Recently, two powerful inhibitors of PLD enzymatic activity derived from halopemide have been described: 5-fluoro-2indolyl des-chlorohalopemide (FIPI) and N-[2-(4-oxo-1-phenyl1,3,8-triazaspiro[4,5]dec-8-yl)ethyl]-2-naphthalenecarboxamide (NOPT). ${ }^{31-33}$

A commonly used animal model is the immunodeficient CB17/ IcrHsd-Prkdc-Scid mouse model, ${ }^{34}$ which is deficient in B and T cells, thus allowing engraftment of allogeneic and xenogeneic cells. In addition, the mammary fat pad ( $\mathrm{mfp}$ ) can be targeted by viral, chemical and physical carcinogens and will yield unique and complex models for neoplastic development. A SCID tumor model based on implantation of human MDA-MD-231 breast cancer cells into the $\mathrm{mfp}$ progresses rapidly ( $<4$ weeks until primary tumor onset) after xenotransplantation. ${ }^{35,36}$

PLD couples survival and migration in tumor cell lines. ${ }^{37}$ Overexpression of wild-type PLD2 has been implicated in EL4 lymphoma metastasis in vivo, whereas overexpression of catalytically inactive PLD2 generated fewer liver metastases

\footnotetext{
${ }^{1}$ Department of Biochemistry and Molecular Biology, Boonshoft School of Medicine, Wright State University School of Medicine, Dayton, OH, USA; ${ }^{2}$ Laboratory Animal Resources, Wright State University School of Medicine, Dayton, OH, USA and ${ }^{3}$ Veterans Affairs Medical Center, Cincinnati, OH, USA. Correspondence: Professor J Gomez-Cambronero, Department of Biochemistry and Molecular Biology, Wright State University School Medicine, 3640 Colonel Glenn Highway, Dayton, OH 45435, USA. E-mail: julian.cambronero@wright.edu
}

Received 19 February 2013; revised 18 April 2013; accepted 21 April 2013; published online 10 June 2013 
compared with control cells. ${ }^{38}$ Recently, Chen et al. ${ }^{39}$ examined the in vivo role of PLD1 in melanoma growth and metastasis, showing that administration of the inhibitor FIPI into wild-type mice or the loss of PLD1 via PLD1 knockout mice led to a significant reduction of tumor metastases. These results implicate the importance of PLD1 in the tumor microenvironment, which aids in tumor growth/metastasis. However, in that work, PLD was not analyzed directly in the tumors or whether the other mammalian isoform, PLD2, contributed toward tumor growth.

In this study, we demonstrate that PLD2 has a role in breast cancer invasion and tumorigenesis in vivo. PLD2 stably silenced in highly invasive breast cancer cells led to tumors derived from these cells being only mildly invasive in SCID mice. Conversely, when PLD2 was overexpressed in low-invasive breast cancer cells and xenotransplanted into SCID mice, more substantial breast tumors arose. Moreover, implanting micro-osmotic pumps containing PLD-specific inhibitors into SCID mice led to a reduction of breast tumors and metastasis following xenotransplantation. Finally, we determined the mechanism of mammary tumor cell invasion and metastasis seen following PLD2 overexpression as being mediated by PA, growth receptor-bound protein 2 (Grb2) and Rac2. We advance here the concept that PLD2 is a key factor for cell invasion that contributes critically to growth and metastasis of breast tumors in vivo. The results from this study will have clear pharmacological implications in humans.

\section{RESULTS}

Knocking down PLD deters invasion of highly aggressive cancer cells It is known that MDA-MB-231 cells are highly invasive and metastatic cancer cells, and some reasons could be due to high PLD activity found in these cells and PLD's involvement in cancer cell survival. ${ }^{37}$ We reasoned that if this were the case, inhibiting PLD2 expression would diminish the highly invasive potential of these cells. To test this hypothesis, we knocked down PLD2 using a targeted lentiviral short hairpin RNA. We created two stable MDA-MB-231 cell lines, one that stably silenced PLD2 expression (MDA-MB-231 shPLD2; Figure 1a) and one infected with an appropriate negative control (MDA-MB-231 shControl). Figure 1b represents the overall effectiveness of PLD2-knockdown, as shown using western blot analysis.

As shown in Figure 1c, we found that cell proliferation of shPLD2-silenced MDA-MB-231 cells decreased as a function of time and a concomitant decrease in PLD catalytic activity
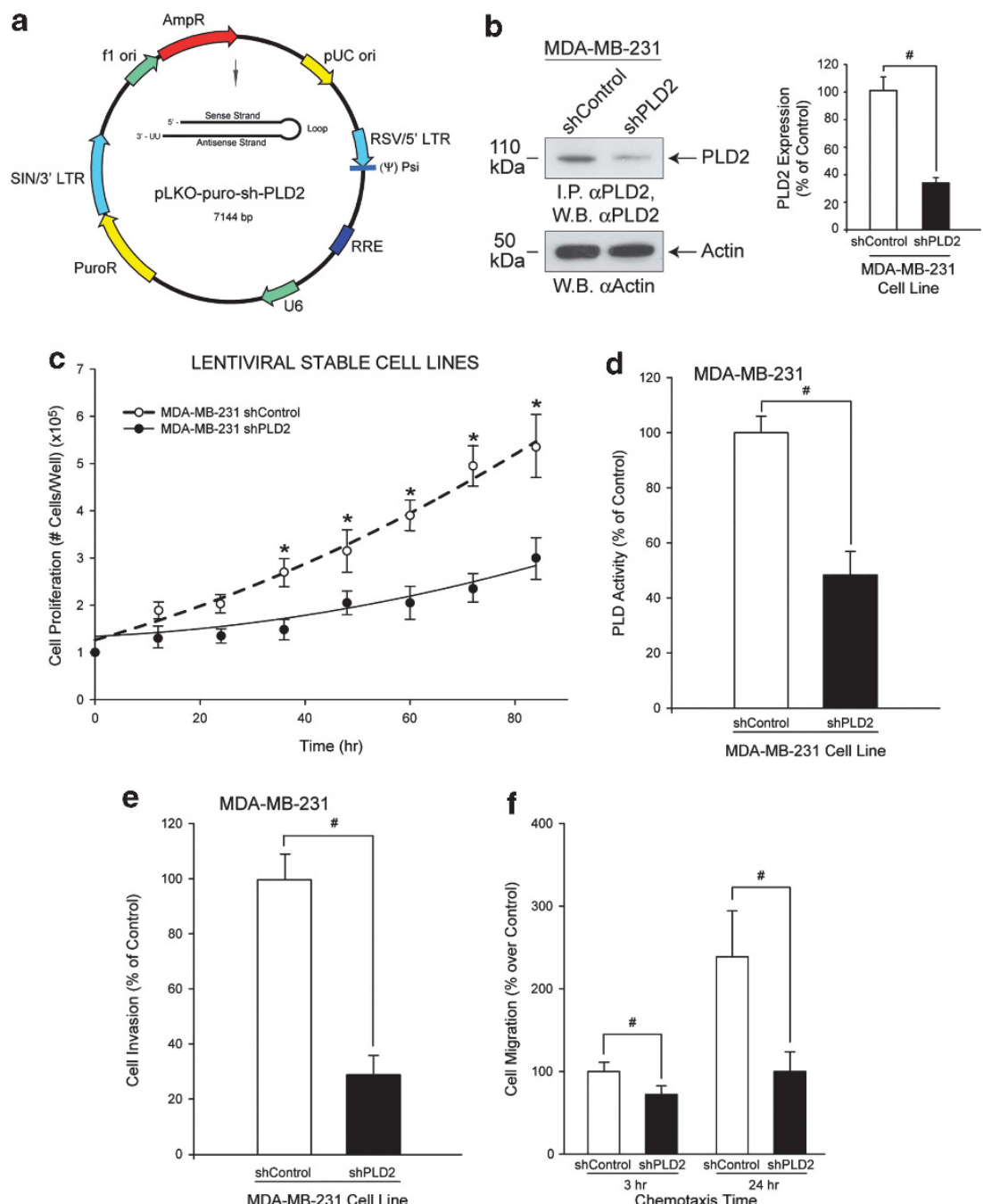

Figure 1. A stably silenced PLD2 MDA-MB-231 cell line using lentiviral short hairpin RNA (shRNA) shows decreased cancer cell invasion (a) Vector map of pKLO-shPLD2. (b) Western-blot analysis of cell lysates from MDA-MB-231 shControl or shPLD2 cells, with anti-PLD2 antibody. (b, inset) Quantification of PLD2 silencing from western blot analysis of cell lysates from MDA-MB-231 shControl or shPLD2 cells. (c) Cell proliferation of puromycin-resistant, stable MDA-MB-231 pKLO cells expressing shPLD2. (d) PLD activity. (e, f) Negative effect of PLD silencing on physiological functions (cell invasion and chemotaxis, respectively). Triplicate results are mean \pm s.e.m. The symbols ${ }^{*}$ and ${ }^{\#}$ denote statistically significant $(P<0.05)$ differences (increases or decreases, respectively) between samples and controls. 
(Figure 1d), cell invasion (Figure 1e) and chemotaxis (Figure 1f) were observed. Thus, these highly aggressive cancer cells have been rendered low-invasive by PLD2 expression that was knocked down by $\sim 70 \%$ and resulted in PLD activity that was decreased by $\sim 55 \%$, which underscores the crucial importance of this molecule in cell invasion.

We next tested if this decrease in aggressiveness was observed in an in vivo mouse model: SCID mice were injected with MDA-MB231 shControl or shPLD2 cancer cells. We found a statistically significant 4-day delay in the onset of measurable primary breast tumor formation in mice injected with MDA-MB-231 pLKO-shPLD2 silenced cells when compared with mice that were injected with the negative MDA-MB-231 shControl cells (Figure 2a). Primary tumor volume was decreased by $65 \%$ after 27 days post-injection (Figure 2b). This difference in primary tumor size was corroborated by the histology of these samples (Figures $2 c$ and d, respectively).

Large subcutaneous solid carcinomas of differing size with central necrosis developed in both sets of mice at the site of tumor injection (primary tumors; Figures $2 c$ and d), whereas metastatic tumors of differing size presented as nodules in well circumscribed subcutaneous lymph glands (Figures $2 e$ and $f$ ). However, we identified metastatic carcinomas with associated neutrophilic infiltration on the pleural surface of the lungs in $\sim 20 \%$ of MDA-MB-231 shControl mice (Figure 2g, arrowhead), whereas mice injected with MDA-MB-231 shPLD2 cells had no lesions within the lungs (Figure $2 \mathrm{~h}$ ) or on the pleural surface (Figure 2i). If by eliminating PLD2, damage is reduced or eliminated, then it can be inferred that the presence of PLD2 was conducive to the metastatic phenotype.

PLD expression changes low-invasive MCF-7 cells to a highinvasive phenotype

Contrary to silencing PLD2 in a highly invasive breast cancer cell line, as just discussed, we sought to perform the opposite experimentation, that is, overexpression of PLD in MCF-7, a lowinvasive and low metastatic cell line. ${ }^{40,41}$ As the PMIEG vector used

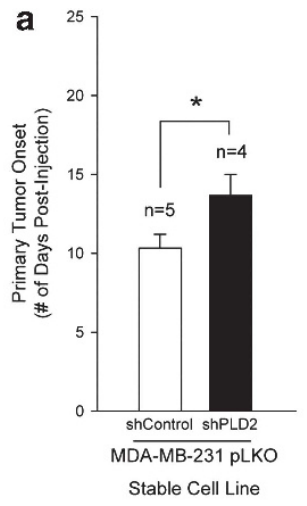

MDA-MB-231 shControl
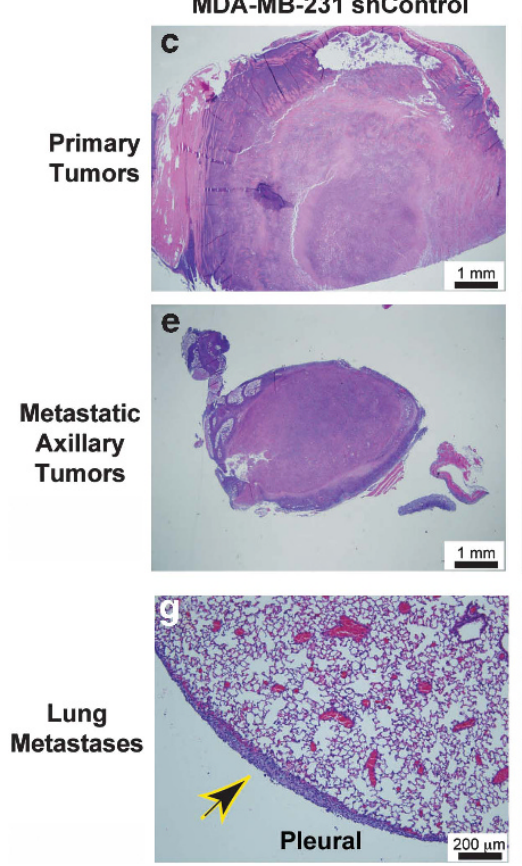

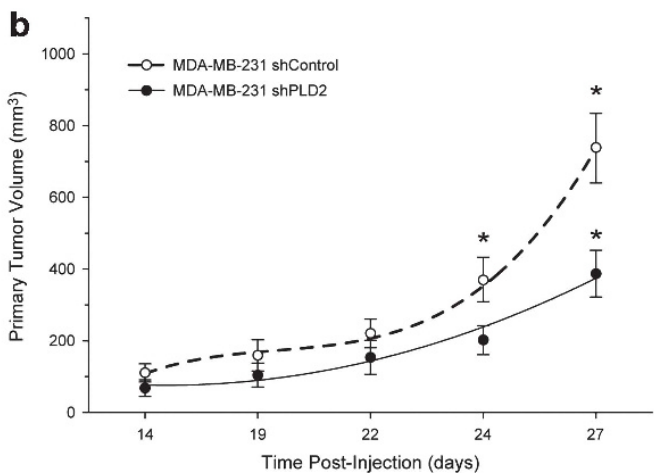

MDA-MB-231 shPLD2
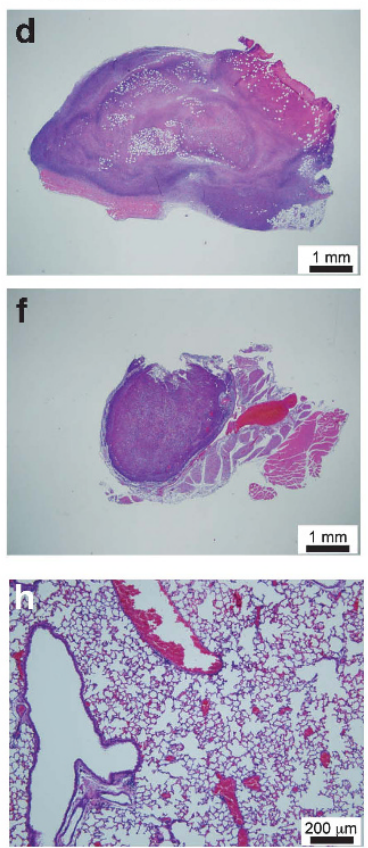

TUMOR

SIZE

Figure 2. PLD2 silencing of SCID mouse metastastic breast cancer model decreases tumor size. Metastatic breast cancer cells MDA-MB-231shPLD2 were implanted into the mfp of immunodeficient 8-week-old female SCID mice. Mammary tumor growth and lung metastasis were determined after the duration of the study (at least 5 weeks). (a) Primary tumor onset (\# days post-injection) for SCID mice injected with MDAMB-231 pKLO (either shControl or shPLD2) stable cell lines. (b) Growth curves of primary tumor volume $\left(\mathrm{mm}^{3}\right)$. The symbol $*$ denotes statistically significant $(P<0.05)$ increases between samples and controls. Representative histology images of primary $(\mathbf{c}$, d) and metastatic tumor sections $(\mathbf{e}, \mathbf{f})$ and lung sections $(\mathbf{g}-\mathbf{i})$ detected by hematoxylin-eosin staining of 3-4 different cross-sections (7-10 $\mu \mathrm{m}$ thick) of tissue from at least three different mice from each group at $\times 10$ magnification, respectively. (c, e, g) Histology of SCID mice injected with MDA-MB231 shControl cells. (d, $\mathbf{f}, \mathbf{h}, \mathbf{i})$ Histology of SCID mice injected with MDA-MB-231 shPLD2 cells. Black and yellow arrowhead denotes presence of pleural carcinoma. (i) $\times 2$ magnification. $(\mathbf{g}, \mathbf{h})$ Scale bar $=200 \mu \mathrm{m}$. $(\mathbf{c}-\mathbf{f}, \mathbf{i})$ Scale bar $=1 \mathrm{~mm}$. 

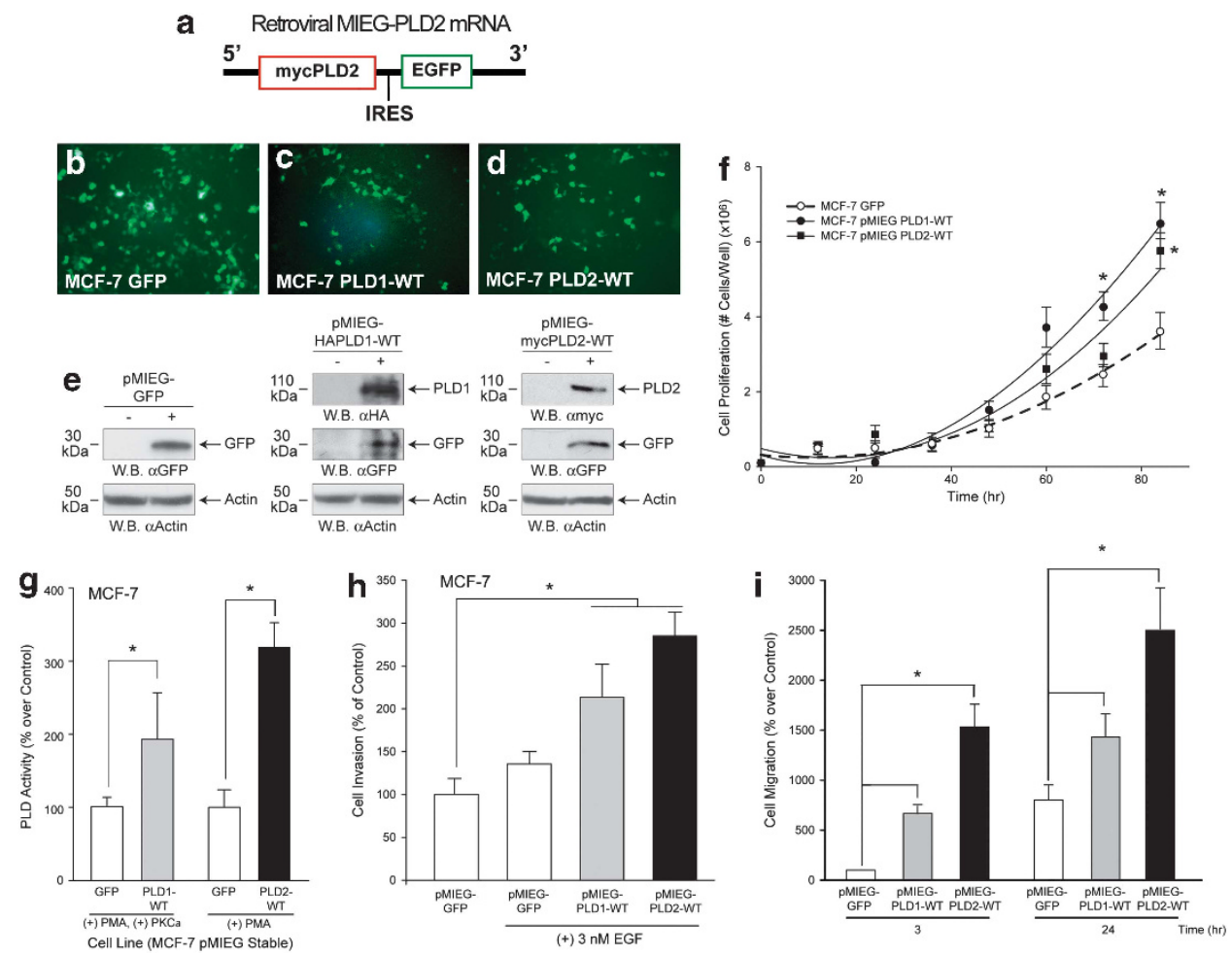

Figure 3. A MCF-7 cancer cell line stably overexpressing recombinant human PLD2 shows enhanced cancer cell invasion. (a) Simplified scheme of MIEG-PLD2 mRNA. (b-d) Immunofluorescence of GFP in puromycin-resistant, stable MCF-7 pMIEG cells overexpressing either GFP vector, PLD1 or PLD2. (e) Western blot analyses of cell lysates. (f) Effect of PLD overexpression on cell proliferation. (g) Effect of PLD overexpression on PLD activity. (h, i) Effect of PLD overexpression on physiological functions (cell invasion and chemotaxis, respectively). Triplicate results are mean \pm s.e.m. ${ }^{*}$ Denotes statistically significant $(P<0.05)$ increases with respect to controls.

to deliver the PLD genes also contained a downstream green fluorescent protein (GFP) construct (Figure 3a), we were able to visually verify stable PLD-overexpressing MCF-7 cells following puromycin selection (Figures $3 \mathrm{~b}-\mathrm{d}$ ) and verified PLD2 induction using western blot analysis (Figure $3 \mathrm{e}$ ). We found that cell proliferation of PLD1- or PLD2-overexpressing MCF-7 cells was increased $\sim 2$-fold when compared with the MCF-7 pMIEG-control cells (Figure 3f), concomitantly with increases in PLD catalytic activity (Figure $3 \mathrm{~g}$ ), cell invasion (Figure $3 \mathrm{~h}$ ) and chemotaxis (Figure 3i).

SCID mice were injected with MCF-7 pMIEG-PLD-overexpressing cancer cells. The presence of PLD1/2 accelerated the onset of detectable primary tumors by $\sim 7$ days (10 versus 17 days) compared with the negative control mice that received MCF-7 pMIEG-GFP cells (Figure 4a). Primary tumor volume was increased 7-10-fold in the MCF-7 pMIEG-PLD injected mice when compared with controls (Figure 4b). Remarkably, PLD overexpression increased the number of metastatic axillary tumors generated in the SCID mice injected with MCF-7 pMIEG stable cells by a factor of 4 to 6 when compared with the negative control GFP vector mice (Figure 4c).

Hematoxylin-eosin-stained cross-sections revealed the presence of tumors generated in the PLD-overexpressing MCF-7 cells. Negative control mice showed small carcinoma infiltration on the pleural surface (Figure $4 d$, arrowhead), whereas mice injected with breast cancer that overexpressed PLD2 had multifocal moderate sized perivascular metastatic carcinomas in the lung parenchyma (Figure $4 \mathrm{f}$, arrowheads). Large subcutaneous solid carcinomas with central necrosis developed in both sets of PLD-overexpressing mice at the site of tumor injection (primary tumors; Figures $4 \mathrm{~h}$ and $\mathrm{i}$, respectively) and were significantly increased in size when compared with the medium-sized carcinoma generated in negative control MCF-7 pMIEG-GFP mice (Figure $4 \mathrm{~g}$ ).

Secondary tumors also presented as nodules in well-circumscribed subcutaneous metastases in axillary lymph nodes (Figures $4 \mathrm{j}-\mathrm{I}$ ) with the largest metastatic tumors being generated in the PLD2-overexpressing mice (Figure 4l) when compared with control and PLD1-overexpressing mice (Figures $4 \mathrm{j}$ and $\mathrm{k}$ ).

PLD inhibitors decrease cancer cell invasion in vitro Recently described PLD inhibitors, FIPI and NOPT, were used to examine invasion through matrigel matrix of both MDA-MB-231 and MCF-7 cells. ${ }^{29,30}$ MDA-MB-231 cancer cells were much more responsive to cell invasion through matrigel matrix (Figure 5a) when compared with MCF-7 cells after epidermal growth factor (EGF) stimulation. We determined that the number of MDA-MB231 (Figures 5b-d) cells that invaded in response to $3 \mathrm{~nm}$ EGF decreased in proportion to increasing inhibitor concentration compared with the non-stimulated cells. Accordingly, we determined the optimal concentration of FIPI, NOPT and apigenin (Figures $5 b-d$ insets, respectively) necessary to inhibit $50 \%$ of chemotactic MDA-MB-231 breast cancer cells in response to EGF (apigenin is not a PLD inhibitor, but it was used here as a positive control for cell invasion).

The results from Figure $5 \mathrm{e}$ show that the endogenous PLD activity of MDA-MB-231 cells were more sensitive to the negative effect of the dual PLD inhibitor, FIPI and the PLD2-specific inhibitor, NOPT, as a function of time when compared with that of the tyrosine kinase inhibitor, apigenin. The decreases in MDA-MB231 cell invasion and PLD2 activity because of PLD inhibition were not a result of a decrease in cell proliferation of the MDA-MB-231 cells, as there was no alteration in proliferation when cell invasion 

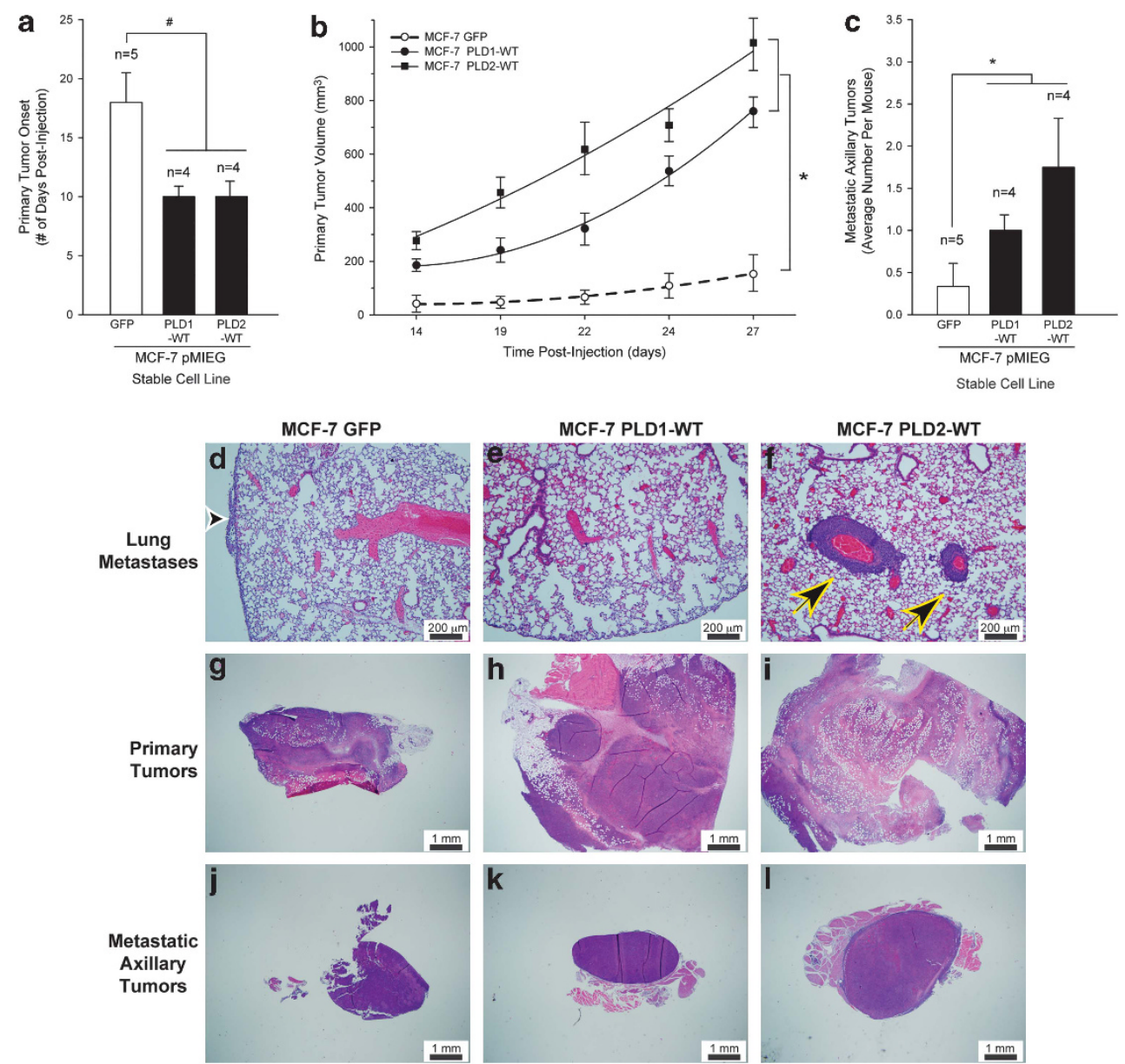

Figure 4. PLD2 overexpression of SCID mouse metastastic breast cancer model increases tumor size. Metastatic breast cancer cells MCF-7 pMIEG were implanted into the mfp of SCID mice. (a) Primary tumor onset (\# days post-injection) of SCID mice injected with MCF-7 pMIEG (either GFP, PLD1 or PLD2) stable cell lines. (b) Effect of PLD overexpression on growth curves of primary tumor volume (mm ${ }^{3}$ ) in the PLDxenotransplanted SCID mice. (c) Increase in the number of metastatic tumors generated in PLD-xenotransplanted SCID mice. The symbols * and ${ }^{\#}$ denote statistically significant $(P<0.05)$ differences (increases or decreases, respectively) between samples and controls. (d-I) Representative histology images of lung sections (d-f), primary tumor sections $(\mathbf{g}-\mathbf{i})$ or metastatic axillary tumor sections (j-I) detected by hematoxylin-eosin staining of 3-4 different cross-sections (7-10 $\mu \mathrm{m}$ thick) of tissue from at least three different mice from each group at $\times 10$ magnification, respectively. (d, $\mathbf{g}, \mathbf{j})$ Histology of SCID mice injected with MCF-7 pMIEG GFP cells. (e, $\mathbf{h}, \mathbf{k})$ Histology of SCID mice injected with MCF-7 pMIEG PLD1 cells. (f, i, I) Histology of SCID mice injected with MCF-7 pMIEG PLD2 cells. Black and white arrowhead denotes presence of pleural carcinoma (d); black and yellow arrowheads point at multifocal perivascular metastatic carcinomas in the lung parenchyma (f). (d-f) Scale bar $=200 \mu \mathrm{m}$. (g-l) Scale bar $=1 \mathrm{~mm}$.

measurements were performed ( $24 \mathrm{~h}$; Figure $5 \mathrm{f})$. However, treatment of cells with the small-molecule inhibitors for $\geqslant 36 \mathrm{~h}$ resulted in a gradual decrease in cell proliferation indicating an anti-proliferation effect of the PLD inhibitors. Further, we determined that MDA-MB-231 cancer cells that overexpress recombinant PLD2-WT were significantly less invasive (Figure $5 \mathrm{~g}$, open bars) in the presence of the small-molecule inhibitors with a concomitant and greater decrease in PLD2 activity (Figure $5 \mathrm{~g}$, filled bars), which supports the data presented in Figure $5 \mathrm{e}$.

PLD inhibitors decrease tumor size and metastases formation in vivo

To test the PLD inhibitors in vivo, SCID mice were implanted with an Alzet micro-osmotic pump containing an inhibitor (Figure 6a) in the left dorsal thoracic area (Figure 6b), and were subsequently xenotransplanted with MDA-MB-231 cancer cells. There was a significant delay $(\sim 1.2-2$-fold $)$ in the onset of primary breast tumors in FIPI- and NOPT-treated mice (Figure $6 \mathrm{c}$ ) and a significant decrease in the volume of primary tumors from the FIPI- and NOPT-treated mice (Figure $6 \mathrm{~d} ; \sim 30$ and $40 \%$, respectively).

In addition, the presence of the small-molecule PLD inhibitors drastically reduced the number of metastatic axillary tumors generated in the SCID mice (Figure 6e). The mice that received NOPT had $\sim 50 \%$ fewer metastatic axillary tumors when compared with the dimethylsulphoxide (DMSO) only negative control mice, while no secondary tumors were observed in the mice that received FIPI or apigenin.

Pathological studies indicated that MDA-MB-231 xenotransplanted SCID mice that received vehicle only (DMSO) had small focal metastatic perivascular lung carcinomas (Figure $6 f$, arrowhead), whereas mice that received either PLD2 inhibitor (FIPI or NOPT) generated small 2-20 cell carcinoma emboli in the alveolar walls (Figures $6 \mathrm{~h}$ and $\mathrm{i}$, arrowheads, respectively). Mice that received apigenin did not form metastatic lung lesions (Figure $6 \mathrm{~g}$ ).

MDA-MB-231 xenotransplanted SCID mice that received DMSO only had primary tumors that were large subcutaneous solid carcinomas with central necrosis invading the $\mathrm{mfp}$ and adjacent 

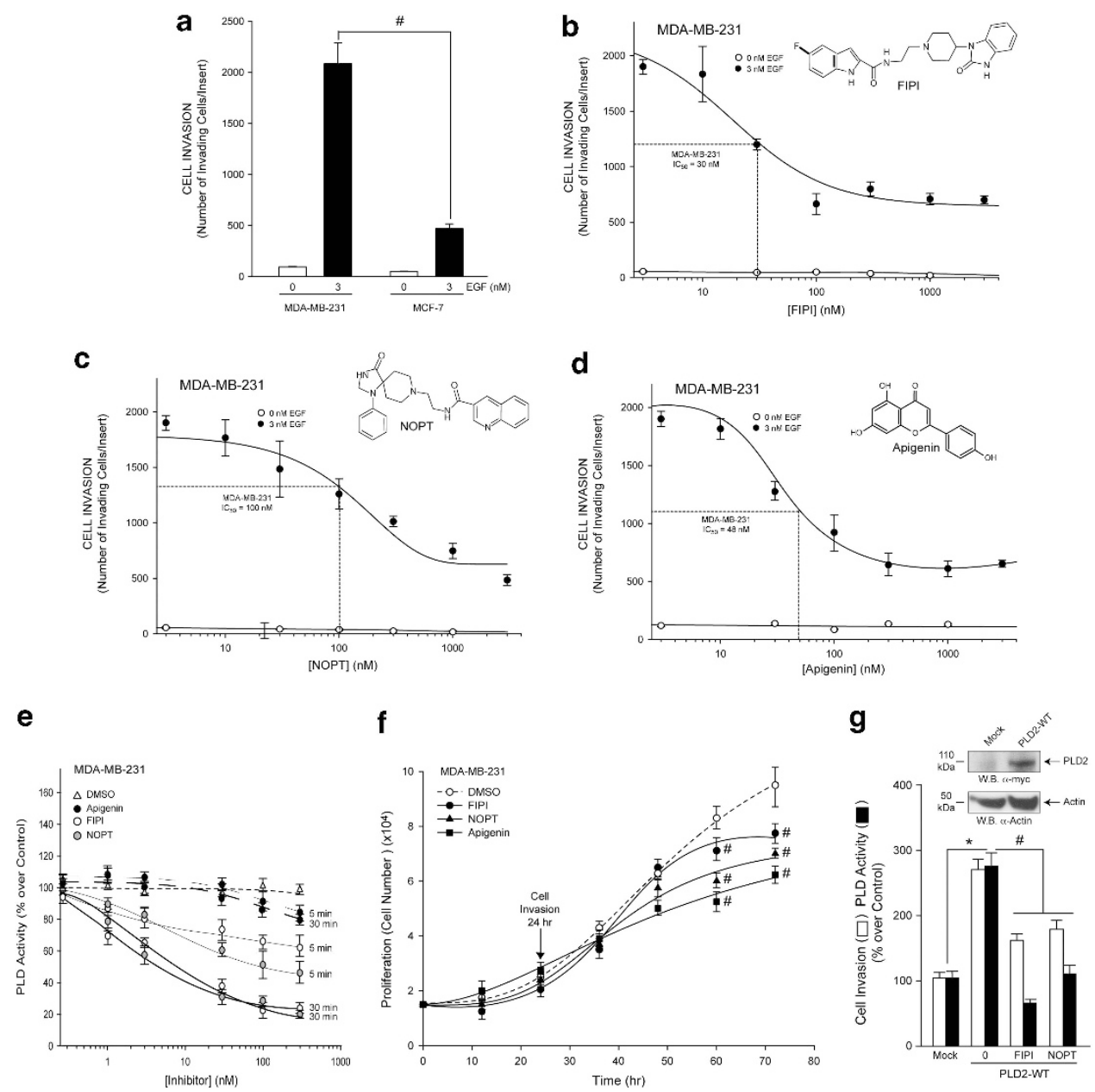

Figure 5. Small-molecule inhibitors, FIPI, NOPT (FIPI: 5-fluoro-2-indolyl des-chlorohalopemid; NOPT: N-[2-(4-oxo-1-phenyl-1,3,8-triazaspiro [4,5]dec-8-yl)ethyl]-2-naphthalenecarboxamide) and apigenin, inhibit cell invasion of two breast cancer cell lines, which correlates to a decreased PLD2 activity independent of cell proliferation. Exponentially growing cells in culture were used for these experiments. (a) Relative difference of cell invasiveness of highly invasive MDA-MB-231 compared with less invasive MCF-7 cells in response to 3 nM EGF. (b-d) Effect of small-molecule inhibitors on cell invasion. (b) FIPI dose response. (c) NOPT dose response. (d) Apigenin dose response. Triplicate results are mean \pm s.e.m. (b, inset) FIPI schematic. (c, inset) NOPT schematic. (d, inset) Apigenin inset. (e) Time-dependent effect of FIPI or NOPT on endogenous PLD activity after incubation for $5 \mathrm{~min}$ or for $30 \mathrm{~min}$ with the inhibitors before the enzymatic assay. (f) Time-dependent effects of small-molecule inhibitors ( $300 \mathrm{~nm}$ concentration of each) on MDA-MB-231 cell proliferation. (g) Effect of $300 \mathrm{~nm}$ concentration of each inhibitor on cell invasion or lipase assay (at $30 \mathrm{~min}$ ) of MDA-MB-231 cancer cells overexpressing recombinant PLD2-WT. Triplicate results are mean \pm s.e.m. The symbols ${ }^{*}$ and ${ }^{\#}$ denote statistically significant $(P<0.05)$ differences (increases or decreases, respectively) between samples and controls.

skeletal muscle (Figure 6j), whereas mice that received smallmolecule inhibitors had primary tumors that were medium to small size subcutaneous solid carcinomas invading adjacent musculature (Figures $6 \mathrm{k}$ and $\mathrm{m}$ ) or medium size subcutaneous solid carcinoma with central necrosis (FIPI, Figure 6I). Thus, PLD inhibitors robustly inhibited tumor onset, tumor size and lung metastasis once again underscoring the cell signaling molecule PLD as crucial in tumor progression.

Mechanism of PLD-derived enhancement of cell invasion and metastasis

In this study, we examined breast cancer cells to determine the underlying mechanism that regulates PLD-mediated cell invasion and metastasis and found that it involves PA, the product of PLD enzymatic activity. In addition to this, PLD could also associate with other signaling molecules that could contribute to the invasive, metastatic phenotype, as described below. In the first approach, to examine for PLD activity, we used a PA sensor (EGFP-
PA-binding domain of Spo $)^{32,42,43}$ to detect in vivo the presence of PA (Figure 7a). We observed that the PA sensor was recruited to a membranous surface in the MDA-MB-231 cells that overexpressed PLD2 but remained nuclear in the MCF-7 that also overexpressed PLD2. The PA sensor was also redistributed to cytoplasmic localizations in silenced cells when compared with cells that overexpressed PLD2 (Figure 7b). These data suggest a lack of PA availability to bind to membrane surfaces under conditions where PLD2 is silenced in cells in general or where PLD2 is endogenously expressed to a lesser extent in the less invasive MCF-7 cells compared with the highly invasive MDA-MB-231 cells. In addition, when lipase-inactive PLD1 (PLD1-K866R) or PLD2 (PLD2-K758R) constructs were stably overexpressed in MCF-7 cells, invasion was significantly reduced because of a lack of PA production by the transfected recombinant PLDs compared with expression of wildtype PLDs (Figure 7c).

In an earlier study from our lab, we found that Wiscott-Aldrich Syndrome protein (WASp) was involved in PLD2-mediated phagocytosis via interaction with the Grb2, which acted as the 
a

b

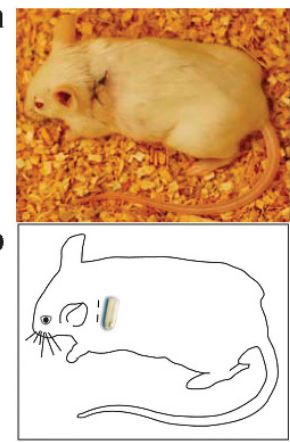

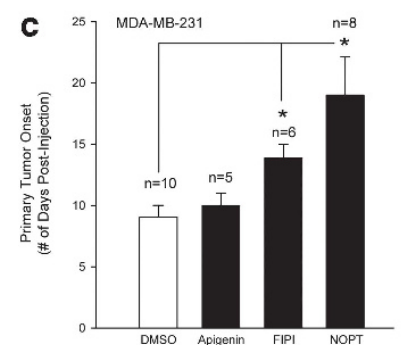

e

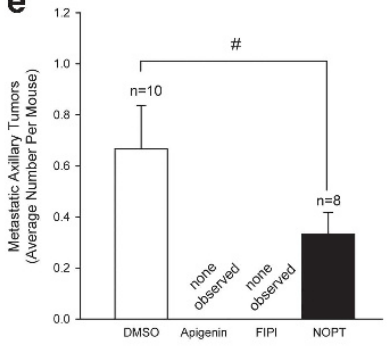

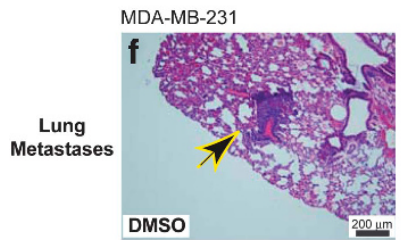
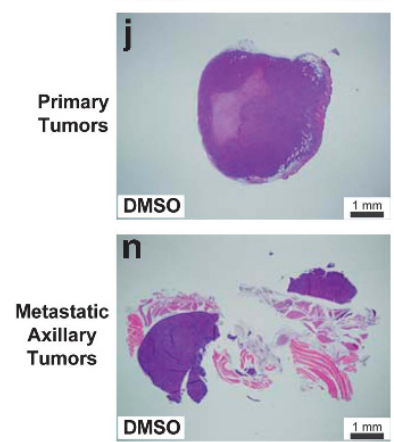
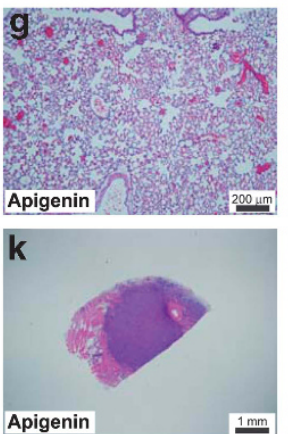

0

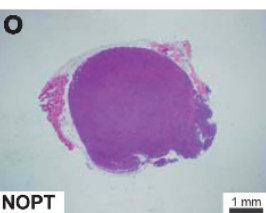

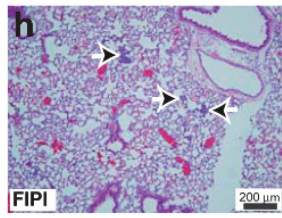
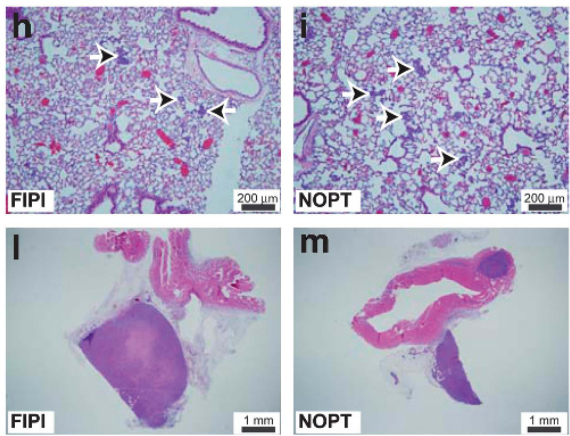

Figure 6. Small-molecule inhibitors reduce tumor size of SCID mouse metastastic breast cancer model. (a) Schematic drawing of Alzet pump implantation in SCID mice. (b) Photographic representation of surgical area on SCID mice after Alzet pump implantation. (c) Delayed primary tumor onset (\# days post-injection) for SCID mice xenotransplanted with MDA-MB-231 cells in the presence of small-molecule inhibitors. (d) Decreased primary tumor volume $\left(\mathrm{mm}^{3}\right)$ following dosing of xenotransplanted SCID mice with small-molecule inhibitors. (e) Reduction in the number of secondary tumors of xenotransplanted SCID mice in the presence of inhibitors. Triplicate results are mean \pm s.e.m. The symbols * and $\#$ denote statistically significant $(P<0.05)$ differences (increases or decreases, respectively) between samples and controls. (f-o) Representative histology images of lung sections (f-i), primary tumor sections $(\mathbf{j}-\mathbf{m})$ or secondary tumor sections (n-o) detected by hematoxylin-eosin staining of 3-4 different cross-sections (7-10 um thick) of tissue from at least three different mice from each group at $\times 10$ or $\times 2$ magnification, respectively. Black and yellow arrowhead denotes presence of small focal metastatic perivascular lung carcinomas (f); black and white arrow heads point at small 2-20 cell carcinoma emboli in the alveolar walls (h-i). (f-i) Scale bar = 200 $\mu$ m. (j-o) Scale $\mathrm{bar}=1 \mathrm{~mm}$.

docking protein between PLD2 and WASp. ${ }^{13}$ Considering this earlier finding, we explored the mechanistic importance of WASp to our in vivo SCID mouse model using transient overexpression of WASp into MCF-7 cells that stably overexpressed PLD2, which were then xenotransplanted into SCID mice. Tumor size at the injection site of mice xenotransplanted with MCF-7 cells expressing PLD2, transient overexpression of a WASp-WT construct or a combination of the two indicate a role for WASP possibly aiding PLD2 in tumorigenesis, which was prevented by PLD inhibitors FIPI and NOPT (Figure 7d).

In addition, we also discovered that once PLD activity is elevated following binding to Grb2-SH2 via PLD2-Y169, PLD2 cooperates with Rac2, and these three proteins are then able to stimulate actin polymerization and subsequent membrane ruffle formation. ${ }^{44}$ Taking this information into consideration, we determined that PLD2 lipase-independent interactions with Grb2 


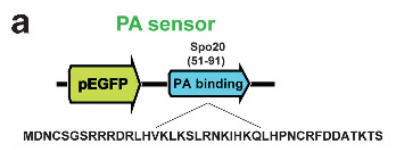

b

b ${ }_{\text {PA Sensor (pEGFP-Spo20-PABD-WT) PA DAPI }}$
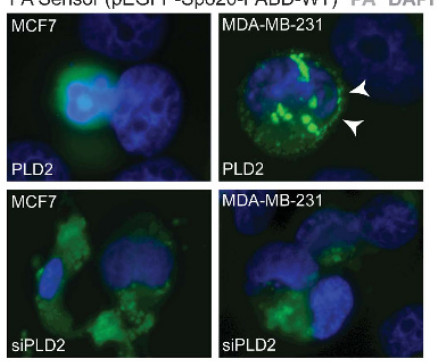

C

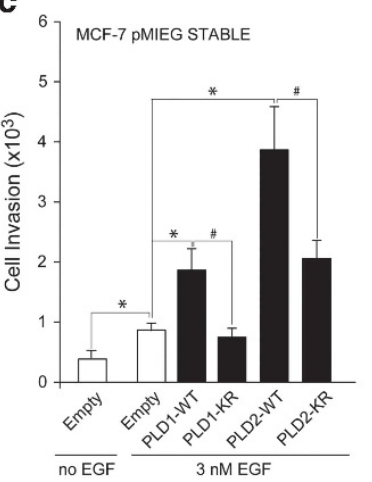

d

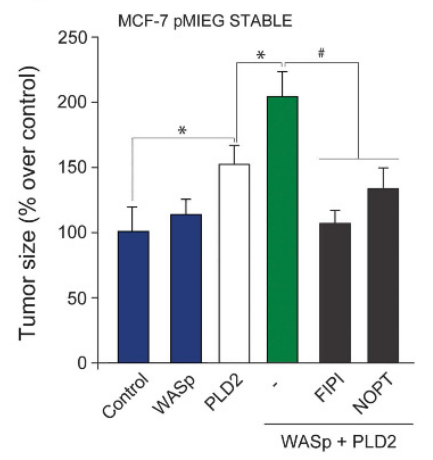

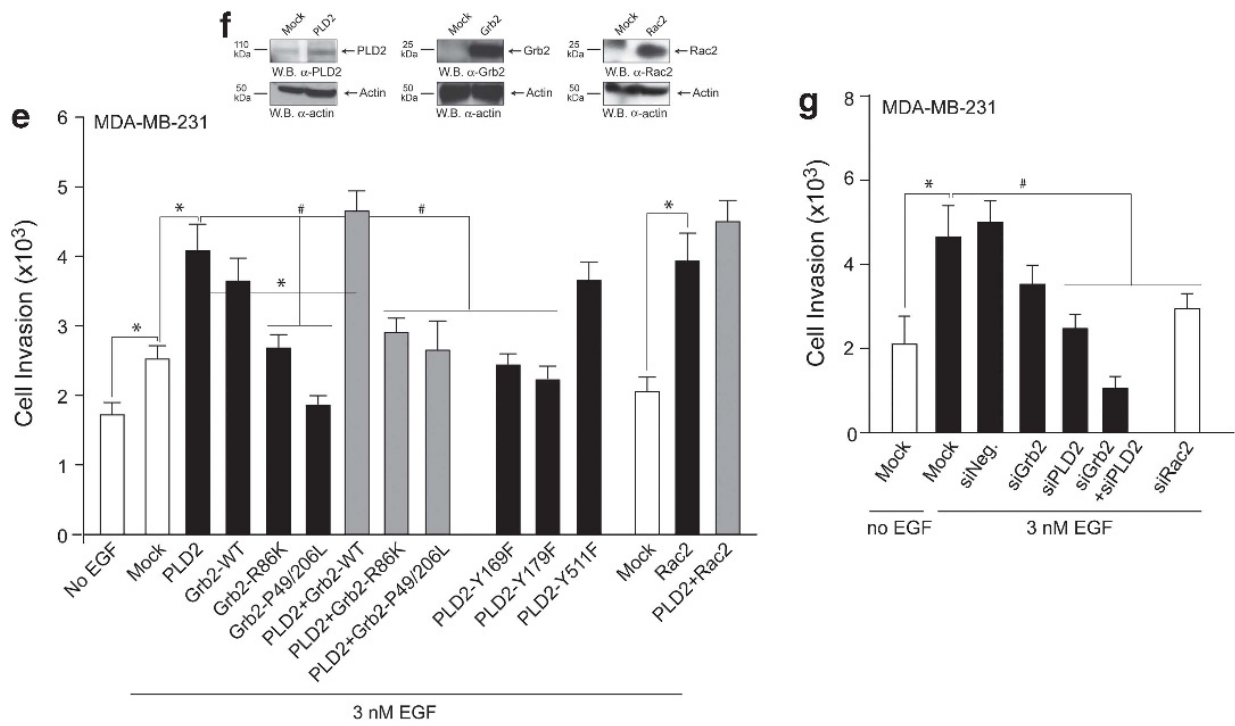

Figure 7. The mechanism that regulates PLD-mediated cell invasion and metastasis involves PA, Rac2 and Grb2. (a) PA sensor used for transfection into MDA-MB-231 or MCF-7 cells. (b) Immunofluorescence of PA sensor expression. White arrowheads denote PA sensor localized to a membranous surface that contained PA. (c) Cell invasion of MCF-7 cells stably expressing lipase-inactive constructs (PLD1-K866R or PLD2K758R). (d) Tumor size of mice injected with MCF-7 cells stably expressing PLD2, a WASp construct or a combination of the two. (e) EGFmediated cell invasion in cells that overexpress PLD2, Grb2 and Rac2 constructs (WT and SH2-binding deficient). (f) PLD2, Grb2 and Rac2 protein expression in MDA-MB-231 cells. (g) EGF-mediated cell invasion in cells silenced with siRNA for Grb2 and/or PLD2 or with siRNA for Rac2. The symbols * and ${ }^{\#}$ denote statistically significant $(P<0.05)$ differences (increases or decreases, respectively) between samples and controls.

and Rac2 also underlie MDA-MB-231 cell invasion, as overexpression of either Grb2 or Rac2 alone or in combination with PLD2 overexpression significantly increased cell invasion of cancer cells (Figure 7e), whereas overexpression of Grb2 mutants that do not bind to PLD2 or WASp significantly reduced invasion (Figure 7e). In contrast, knockdown of Grb2 in conjunction with knockdown of PLD2 virtually abrogated invasion, as did knockdown of Rac2 gene expression (Figure $7 \mathrm{~g}$ ).

In addition to MDA-MB-231 and MCF-7 breast cancer cells, we sought to investigate if our findings were relevant to other cell lines. The data presented in Figure 8a show that MTLn3 ${ }^{41}$ (rat breast cancer cells) demonstrate elevated cell invasion particularly with the overexpression of PLD2, Grb2 and WASP. Two other cancer cell lines, AML14-eosinophils (AML-14-Eo) ${ }^{45}$ and HL-60 neutrophilic (HL60-neut), both leukemic, also displayed similar patterns. Thus, the mechanistic findings could be extrapolated to other cell lines.

A summary of the study findings is presented in Figure 8b, incorporating the chemical inhibitors, in vitro and in vivo studies. Further, we have found that the mechanism of PLD2-mediated mammary tumor metastasis relies on both PA generated by PLD2 and on the interaction with protein-binding partners, such as WASp, Grb2 and Rac2 that serve to upregulate actin polymerization and increase cell invasion.

\section{DISCUSSION}

This study provides evidence that the signaling protein PLD2 is integral for human breast cancer progress in vivo by leading to increased tumor cell growth and invasion. We conducted a controlled study in SCID mice and the pathology examinations showed that PLD contributes to growth, invasion and metastases in vivo.

Using the metastatic model of SCID mice, we investigated the effects of short hairpin RNA as a means to constitutively silence PLD2 expression in highly invasive cancer cells (MDA-MD-231) and stable overexpression of PLD in low-invasive cancer cells (MCF-7). We found that PLD2 knockdown in MDA-MB-231 breast cancer cells significantly abrogated tumor growth and lung metastases in SCID mice, whereas stable transduction of PLD2 in MCF-7 breast cancer cells significantly augmented tumor growth in SCID mice. Overexpression of lipase active PLD2 in lymphoma cells has been 
a

\begin{tabular}{|c|c|c|c|}
\hline Transfection & MTLn3 & HL60-Neut & $\begin{array}{l}\text { AML14- } \\
\text { Eo }\end{array}$ \\
\hline Control (Mock) & $100 \pm 11$ & $100 \pm 10$ & $100 \pm 7$ \\
\hline PLD2-WT & $163_{*}^{ \pm 11}$ & $145_{*} 14$ & $151_{*} \pm 12$ \\
\hline PLD2-K758R & $112 \pm 7$ & $93 \pm 5$ & $120 \pm 8$ \\
\hline WASp-WT & $129 \pm 8$ & $118 \pm 12$ & $140_{*}^{ \pm 9}$ \\
\hline Grb2-WT & $114 \pm 7$ & $140 \pm \frac{10}{*}$ & $124 \pm 13$ \\
\hline $\begin{array}{l}\text { PLD2 } \rightarrow \text { Grb2 } \\
\rightarrow \text { WASp }\end{array}$ & $205 \frac{ \pm}{*}$ & $\underset{*}{182 \pm 11}$ & $217 \pm \frac{14}{*}$ \\
\hline
\end{tabular}

b
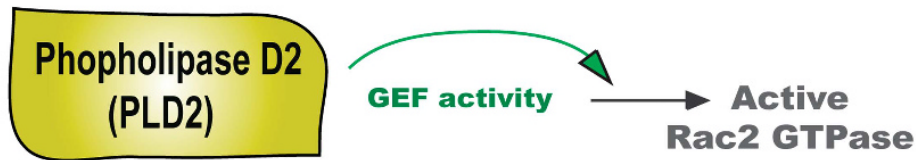

Lipase activity $\mathrm{PC}$<smiles>C=CC(C)=C1CCCCC1</smiles>

PLD2 inhibitors
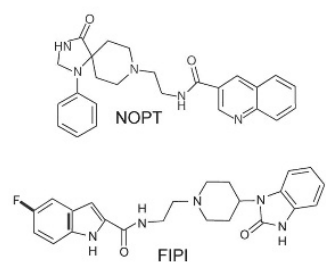

Inhibitors of PLD activity reduce the size of breast cancer tumors and metastasis

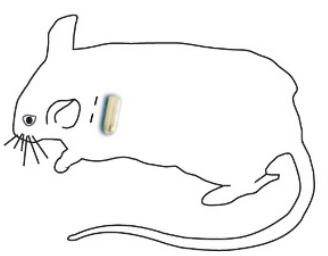

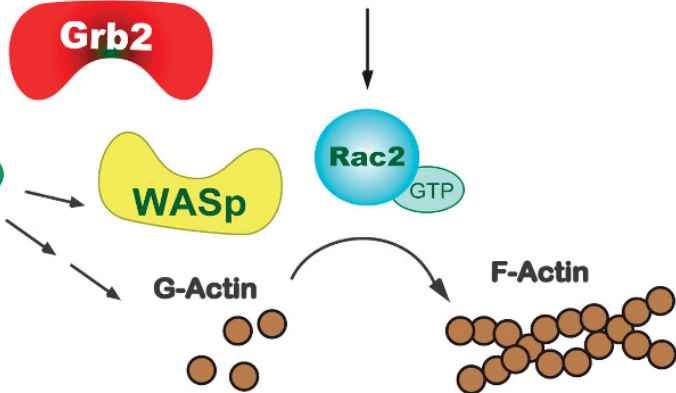

Coll Invasion

1

Metastasis

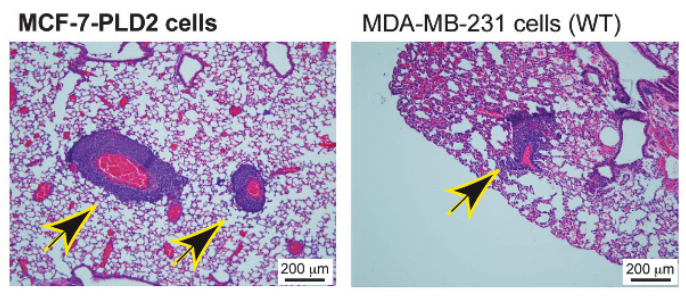

Low invasive cells MCF-7 (left) develop very large metastasis when they are overexpressing the PLD2 gene, even more than highly metastatic MDA-MB-231 cells (right)

Figure 8. Model for the mechanism that regulates PLD-mediated metastasis. (a) Cell invasion (MTLn3) or cell migration (HL60 and AML14) following overexpression of signaling molecules in three cancer cell lines other than MDA's or MCF's. Asterisks represent significant increase $(P<0.05)$. (b) Model that summarizes graphically the findings of this study (histological samples are from Figures $4 \mathrm{f}$ and $6 \mathrm{f})$.

documented in the generation of liver metastases in vivo, whereas overexpression of lipase-inactive PLD2 inhibited liver metastases compared with control lymphoma cells. ${ }^{38}$ This report and the data herein support the importance of catalytically active PLD2 to the metastatic process.

In addition, it has been documented in $\mathrm{Pld} 1^{-1-}$ mice that tumor vascularization of mouse melanoma or lung carcinoma was significantly abrogated as a result of PLD downregulation in the tumor environment (that is, host cells), ${ }^{39}$ but these injected tumor cells had PLD1 and PLD2 expression. In the study reported herein, the environment has normal expression of PLD (that is, wild-type mice), but we are studying PLD expression (or the lack of) directly in the tumor, as the injected cells have been engineered to overexpress or suppress PLD2. Both of these studies (Chen et al. ${ }^{39}$ and here) complement each other and give a more complete picture of the key role of PLD1 and PLD2 in tumorigenesis and metastasis.

We also studied the effects of small-molecule PLD inhibitors on tumor growth and the development of lung metastasis. FIPI is a derivative of halopemide that inhibits both PLD isoforms and interferes with PLD regulation of F-actin cytoskeleton reorganization, cell spreading and chemotaxis. ${ }^{31,32}$ The other PLD enzymatic activity inhibitor, NOPT, inhibits the PLD2 isoform, both in vitro and in cells and is also effective as a PLD1 inhibitor at higher concentrations. ${ }^{33}$ In vitro, NOPT strongly inhibits the invasive migration of breast cancer cells in Transwell assays, shown for the 
first time by Scott et al. ${ }^{33}$ Very interestingly, Scott et al. ${ }^{33}$ present PLD as an useful target in blocking tumor cell invasion, which is what we have achieved in this study in both in vitro cell invasion and in in vivo situations.

Chen et al. $^{39}$ showed elegantly that administration of FIPI to PLD1 ${ }^{-1-}$ mice inhibited tumor growth and metastasis. In this study, we found that PLD inhibitory compounds deterred cell invasion, tumor growth and the incidence of metastatic tumors in xenotransplanted SCID mice, and that the novel approaches of deletion or overexpression of the PLD isoform PLD2 and follow-up in vivo, demonstrates a crucial bearing of PLD2 on tumorigenesis. We advance here the concept that PLD2 is a key factor for cell invasion that contributes critically to growth and metastasis of breast cancer cells in vivo, which has potential clinical utility in human breast cancer treatment.

PLD confers rapamycin resistance ${ }^{19}$ and survival signals in human cancer cells with activated $\mathrm{H}$-Ras or $\mathrm{K}-\mathrm{Ras}^{23}$ possibly due to PA involvement. We have seen that the mechanism of PLDmediated tumor invasion and metastasis involves PA and the association of PLD2 with Rac2 and actin. Support of PLD's role in non-catalytic functions has been presented whereby PLD2 can still act as an adaptor protein for the Grb2, ${ }^{13}$ binds onto Rac2 and affects cell membrane ruffling and cell growth. ${ }^{44,46}$ We propose that PLD-synthesized PA is directly involved in regulating actin polymerization of invasive mesenchymal cells. As known, cancer cells escape the initial tumor when the tumor reaches a certain size, becoming invasive and highly motile and gain entry into the systemic circulation by reaching a nearby capillary or lymph vessel. As in the epithelial-to-mesenchymal transition, cancer cells become amoeboid, free-floating and highly mobile like leukocytes, our knowledge amassed in the last 5-7 years on PLD-derived chemotaxis action will be directly implicated in cell invasion in vivo.

Our laboratory ${ }^{13,44,47,48}$ and others ${ }^{49-53}$ have provided ample evidence of PA-related actin polymerization. The implication of novel molecules such as Grb2, Sos, Wasp and Rac2 on cell migration has been previously reviewed. ${ }^{30,54}$ Although we acknowledge that PLD1 is involved in increased tumor cell invasion and tumorigenesis in our model that relied on overexpression of PLD1 in the less invasive MCF-7 cells, we did not focus on any mechanistic control of PLD1 in this study, as our primary focus was on that of PLD2.

In conclusion, this study documents the first proof of a role for PLD2 in breast tumor progression and metastasis and has provided insight into the mechanism of action. PLD2 could be a marker of metastatic progression ${ }^{38,55,56}$ and a viable target for anti-breast tumor therapy. This report provides the foundation for further studies of the molecular and cellular mechanisms by which PLD2 mediates tumor growth, invasion and metastasis in vivo. Our results also provide evidence that targeting PLD is a good candidate for future therapeutic and clinical applications aimed at reducing human breast cancer metastasis.

\section{MATERIALS AND METHODS}

\section{Cells and cell culture}

MDA-MB-231 cells were obtained from ATCC (Manassas, VA, USA). MCF-7 cells were from Dr Steven J Berberich (Wright State University). GP2-293 retroviral packaging cells, MCF-7 and MDA-MB-231 cells were cultured in Dulbecco's modified Eagle's medium (DMEM) supplemented with 10\% (v/v) fetal bovine serum. Cells were maintained at $37^{\circ} \mathrm{C}$ in an incubator with a humidified atmosphere of $5 \% \mathrm{CO}_{2}$.

Lentiviral production of MDA-MB-231 cell line to stably silence PLD2

Lentivirus was produced by the co-transfection of 293FT cells with a pLenti vector (pKLO-shControl or pKLO-shPLD2) and lentiviral packaging mix (Invitrogen, Carlsbad, CA, USA), according to the manufacturer's instructions. Lentivirus-containing supernatant was harvested 48 -h posttransfection, purified by centrifugation and stored at $-80^{\circ} \mathrm{C}$. For viral transductions, $1 \mathrm{ml}$ of the pKLKO-shControl or pPLKO-shPLD2 lentiviruses was incubated with MDA-MB-231 mammalian cells in the presence of $4 \mu \mathrm{g} /$ $\mathrm{ml}$ polybrene overnight at $37^{\circ} \mathrm{C}$ in a humidified cell culture incubator. Twenty-four hours post-infection, cells were screened for target expression using a final concentration of $300 \mathrm{ng} / \mathrm{ml}$ puromycin for 7 days at which time mock MDA-MB-231 pKLO-shControl or PLD2-silenced MDA-MB-231 pKLO-shPLD2, puromycin-resistant cells were cultured in complete media (DMEM, 10\% fetal calf serum, pen-strep). After 1 month of stable growth in complete media, verification of target cells was conducted by western blot analysis.

Cloning and production of a MCF-7 cancer cell line stably overexpressing recombinant human PLD2

To create the stable overexpression of recombinant PLD protein, a $5^{\prime}$ Sall and a $3^{\prime}$ Hindlll site were introduced in a pcDNA3.1-mycPLD2-WT PLD2 template. The PCR product was amplified with plaque-forming unit DNA polymerase. A pMIEG retroviral vector was prelinearized from the manufacturer and was recombined with the PCR product of interest using the In-Fusion Dry-Down PCR Cloning Kit (Clontech, Mountain View, CA, USA) and sequenced to ascertain expression of the correct DNA sequence. GFP only, PLD1 or PLD2 cloned into the MIEG retroviral vector were referred to as either 'pMIEG-GFP', 'pMIEG-PLD1' or 'pMIEG-PLD2' and were used to generate replication-deficient retroviral particles in vitro. The pMIEG vectors (GFP, HAPLD1 or mycPLD2) were transfected into GP2-293 mammalian cells in the presence of the pVSV-G vector. Cell culture supernatants containing the replication-deficient viral particles were harvested. Retrovirus was incubated with MCF-7 human breast cancer cells to produce stable cell lines overexpressing PLD or only the negative control GFP vector in the presence of $4 \mu \mathrm{g} / \mathrm{ml}$ polybrene. Verification of target cells overexpressing PLD was confirmed using western blot analysis.

\section{Cell invasion assays}

MDA-MB-231 and MCF-7 cells were serum starved for $2 \mathrm{~h}$ and resuspended at a concentration $1.5 \times 10^{6} \mathrm{cells} / \mathrm{ml}$ in chemotaxis buffer (DMEM $+0.5 \%$ bovine serum albumin). Approximately $3 \times 10^{5}$ cells were applied to the upper chambers of $8 \mu \mathrm{m}$ PET matrigels (24-well format) with a $6.5 \mathrm{~mm}$ diameter membrane. Final concentration of chemoattractant used was 0 or $3 \mathrm{~nm}$ EGF in $500 \mu \mathrm{l}$ of chemotaxis buffer placed in the lower wells of 24-well plates. Cell invasion assays were incubated for $6 \mathrm{~h}$ (MDA-MB-231) or overnight (MCF-7) at $37{ }^{\circ} \mathrm{C}$ in a humidified $5 \% \mathrm{CO}_{2}$ cell culture incubator. Cells were scraped from the matrigel insert and then stained for $1 \mathrm{~h}$ with hematoxylin.

\section{Cell migration assay}

Cells were resuspended at a density of $5 \times 10^{5}$ cells $/ \mathrm{ml}$ in chemotaxis buffer (DMEM with $0.1 \%$ bovine serum albumin). A total of $200 \mu \mathrm{l}$ was placed in the upper chambers (or inserts) of transwell inserts that were separated from the lower wells by a $6.5-\mathrm{mm}$ diameter, $8-\mu \mathrm{m}$-pore-size polycarbonate membrane. For the study of chemotaxis, EGF was prepared fresh the day of the experiment in $1 \times$ phosphate-buffered saline- $0.1 \%$ bovine serum albumin, $\mathrm{pH}, 7.2$, at a stock concentration of $1 \mu \mathrm{m}$. When ready for chemotaxis, EGF was diluted to a $3 \mathrm{~nm}$ working concentration in $500 \mu \mathrm{l}$ of chemotaxis buffer and placed into the lower wells of 24-well plates. Cell migration inserts were incubated for $1 \mathrm{~h}$ at $37^{\circ} \mathrm{C}$ under a $5 \%$ $\mathrm{CO}_{2}$ atmosphere. The number of cells that migrated to the lower wells was calculated by placing 10- $\mu$ l aliquots on a hemocytometer and counting four fields in duplicate.

\section{Cell proliferation assay}

MDA-MB-231 cells were plated into 24 -well plates $24 \mathrm{~h}$ before use. If relevant, then duplicate wells were untreated (DMSO) or treated with 300 nм FIPI or 300 nм NOPT. After incubation, cells were washed $2 \times$ with phosphate-buffered saline and trypsinized with the final volume brought up to $1 \mathrm{ml} /$ well using complete DMEM containing 10\% fetal calf serum. Cell proliferation in the absence of inhibitors was determined for puromycinresistant MDA-MB-231 cells stably silencing PLD2 (MDA-MB-231 pKLOshPLD2) or MCF-7 cells stably overexpressing PLD (MCF-7 pMIEG-HA-PLD1 or MCF-7 pMIEG-mycPLD2). Duplicate wells of cells were plated into 24-well plates, incubated and trypsinized; viable cells counted $/ \mathrm{ml}$ cells. 
PLD activity assay

MDA-MB-231 cell lysates in the absence or presence of small-molecule inhibitors were processed for PLD activity in PC8 liposomes and $\left[{ }^{3} \mathrm{H}\right] \mathrm{n}$ butanol beginning with the addition of the following reagents (final concentrations): $3.5 \mathrm{~mm}$ PC8 phospholipid, $45 \mathrm{~mm}$ HEPES (pH 7.8) and $1.0 \mu \mathrm{Ci}\left[{ }^{3} \mathrm{H}\right] n$-butanol in a liposome form, to accomplish the transphosphatidylation reaction of PLD. Samples were incubated for $20 \mathrm{~min}$ at $30^{\circ} \mathrm{C}$ with continuous shaking. Addition of $0.3 \mathrm{ml}$ ice-cold chloroform/methanol $(1: 2)$ stopped the reactions. Lipids were then isolated and resolved by thin layer chromatography. The amount of $\left[{ }^{3} \mathrm{H}\right]$-PBut that co-migrated with PBut standards $(R f=0.45-0.50)$ was measured by scintillation spectrometry.

\section{SCID mice}

Eight-week-old female B- and T lymphocyte-deficient SCID/CB17 mice (C.B117/lcrHsd-Prkdc-Scid) were purchased form Harlan Laboratories (Indianapolis, IN, USA). Mice were given a week to acclimate to the animal facility before they were studied. To minimize the risk of any exogenous infection, the SCID mice were maintained and cared for in sterile, static micro-isolation cages. Mice received irradiated food (Harlan Teklad 2920X, Harlan Laboratories) and sterile water ad libitum. All animal procedures and housing occurred in a facility accredited by AAALAC International (Frederick, MD, USA), and all experimental procedures involving animals were reviewed and approved by Wright State University's Institutional Laboratory Animal Care and Use committee.

\section{Alzet miniature osmotic pumps}

In experiments studying the effects of PLD inhibitors, Alzet miniature osmotic pumps (Durect Corp., Cupertino, CA, USA) were used as an inhibitor-delivery system. The pumps were aseptically filled with either the vehicle (50\% DMSO) or inhibitory compound at a concentration that would deliver $1.8 \mathrm{mg} / \mathrm{kg} /$ day of apigenin, FIPI or NOPT at a rate of $0.11 \mu \mathrm{l} / \mathrm{h}$ for $4-5$ weeks. For FIPI, this concentration is equivalent to $\sim 300 \mathrm{~nm}$ given a $5.5 \mathrm{~h}$ half-life and $18 \%$ bioavailability, ${ }^{31}$ which exerts full inhibition on PLD2. ${ }^{32}$ For NOPT, the current half-life is not available from the literature, but it should be sufficient to inhibit PLD2, especially since the IC ${ }_{50}$ for PLD1 is in the micromolar range and is much greater than PLD2. ${ }^{33}$ The half-life of apigenin is not currently known in mice, but it is $>12 \mathrm{~h}$ in humans. ${ }^{57}$ Therefore, $1.8 \mathrm{mg} / \mathrm{kg} /$ day for each inhibitor should yield full inhibition of PLD or tyrosine kinases. Filled pumps were equilibrated in sterile $0.9 \%$ saline at room temp for $18 \mathrm{~h}$ to reach steady state and optimal pump performance before implantation. After equilibration, pumps were aseptically implanted subcutaneously on the left dorsal thoracic area of the SCID mice while under isoflurane anesthesia. Carprofen $(5 \mathrm{mg} / \mathrm{kg})$ was administered for analgesia one time subcutaneously at the time of surgery.

\section{Xenotransplants of SCID mice and metastastic breast cancer models}

SCID mice that were xenotransplanted with cell lines that either over- or under-expressed PLD only in the absence of the small-molecule inhibitors were injected with 4-6 $\times 10^{6}$ cells (either MDA-MB-231 pKLO-shControl, MDA-MB-231 pKLO-shPLD2, MCF-7 pMIEG-GFP, MCF-7 pMIEG-HAPLD1 or MCF-7 pMIEG-mycPLD2) in sterile Hank's balanced salt solution $+0.5 \%$ bovine serum albumin in the left $\mathrm{mfp}$ with the mice under isoflurane anesthesia. Tumors were measured every $2-3$ days throughout the study with a digital caliper and volume values were calculated with the formula $V=(L)(w 2) / 2$. Approximately 4 weeks after injection of cancer cells, mice were humanely killed. The primary breast tumor, lung and any metastatic axillary tumors were surgically excised and final dimensions measured. The tissues were then fixed and stained with hematoxylin and eosin. For SCID mice that received delivery of small-molecule inhibitors via implanted alzet pumps, mice were xenotransplanted one day after implantation. Approximately 4-6 $\times 10^{6} \mathrm{MDA}-\mathrm{MB}-231$ human breast cancer cells in sterile Hank's balanced salt solution $+0.5 \%$ bovine serum albumin were injected into the left $\mathrm{mfp}$ with the mice under isoflurane anesthesia.

\section{GFP-based PA sensor}

Sporulation-specific protein 20 (Spo20) is a yeast protein required for the fusion of exocytic vesicles with the plasma membrane during yeast sporulation through its interactions with the SNARE complex, ${ }^{58-60}$ which contains an inhibitory region that sequesters the protein in the nucleus ${ }^{60,61}$ and a positive regulatory region that binds to phospholipids (especially PA) in the cell membrane, termed the PA-binding domain (PABD). Cloning of the PABD into the pEGFPC1 vector leading to pEGFP-Spo20PABD-WT for use in microscopy of mammalian cells was documented in Su et $a l^{32}$ and Zeniou-Meyer et al. ${ }^{42}$

\section{Statistical analysis}

Data are presented as mean + s.e.m. The difference between means was assessed by the single factor analysis of variance test. Probability of $P<0.05$ indicated a significant difference.

\section{CONFLICT OF INTEREST}

The authors declare no conflict of interest.

\section{ACKNOWLEDGEMENTS}

This work has been supported by grant HL056653 from the National Institutes of Health (NIH/NHBLI) to JGC and from grants 229102 from Wright State University Boonshoft School of Medicine, and 668372 from the State of Ohio Research Incentive, also to JGC. We thank Dr Mary C Dinauer and Christophe Marchal for their help generating the PMIEG-PLD vectors and Dr Michael Frohman for providing the PA sensor and to Dr Frohman and to $\mathrm{Dr} \mathrm{H}$ Alex Brown for guidance in the use of inhibitors. We also thank Dr Cambronero's lab members Qing Ye, Sam Kantonen, Madhu Mahankali, Nate Hatton and Ramya Ganesan, for their excellent help and care with the mice studies.

\section{REFERENCES}

1 Bray F, Ren JS, Masuyer E, Ferlay J. Global estimates of cancer prevalence for 27 sites in the adult population in 2008. Int J Cancer 2013; 132: 1133-1145.

2 Benson JR, Jatoi I. The global breast cancer burden. Future Oncol 2012; 8: 697-702.

3 Scully OJ, Bay BH, Yip G, Yu Y. Breast cancer metastasis. Cancer Genomics Proteomics 2012; 9: 311-320.

4 Lorusso G, Ruegg C. New insights into the mechanisms of organ-specific breast cancer metastasis. Semin Cancer Biol 2012; 22: 226-233.

5 Steeg PS. Tumor metastasis: mechanistic insights and clinical challenges. Nat Med 2006; 12: 895-904.

6 Hanahan D, Weinberg RA. Hallmarks of cancer: the next generation. Cell 2011; 144: 646-674.

7 Kang DW, Min do S. Platelet derived growth factor increases phospholipase D1 but not phospholipase D2 expression via NFkappaB signaling pathway and enhances invasion of breast cancer cells. Cancer Lett 2010; 294: 125-133.

8 Reich R, Blumenthal M, Liscovitch M. Role of phospholipase D in laminin-induced production of gelatinase A (MMP-2) in metastatic cells. Clin Exp Metastasis 1995; 13: 134-140.

9 Deryugina El, Quigley JP. Matrix metalloproteinases and tumor metastasis. Cancer Metastasis Rev 2006; 25: 9-34.

10 Williger BT, Ho WT, Exton JH. Phospholipase D mediates matrix metalloproteinase-9 secretion in phorbol ester-stimulated human fibrosarcoma cells. J Biol Chem 1999; 274: 735-738.

11 Park MH, Ahn BH, Hong YK, Min do S. Overexpression of phospholipase D enhances matrix metalloproteinase-2 expression and glioma cell invasion via protein kinase $\mathrm{C}$ and protein kinase A/NF-kappaB/Sp1-mediated signaling pathways. Carcinogenesis 2009; 30: 356-365.

12 Taves J, Rastedt D, Canine J, Mork D, Wallert MA, Provost JJ. Sodium hydrogen exchanger and phospholipase $D$ are required for alpha1-adrenergic receptor stimulation of metalloproteinase-9 and cellular invasion in CCL39 fibroblasts. Arch Biochem Biophys 2008; 477: 60-66.

13 Kantonen S, Hatton N, Mahankali M, Henkels KM, Park H, Cox D et al. A novel phospholipase D2-Grb2-WASp heterotrimer regulates leukocyte phagocytosis in a two-step mechanism. Mol Cell Biol 2011; 31: 4524-4537.

14 Knapek K, Frondorf K, Post J, Short S, Cox D, Gomez-Cambronero J. The molecular basis of phospholipase D2-induced chemotaxis: elucidation of differential pathways in macrophages and fibroblasts. Mol Cell Biol 2010; 30: 4492-4506.

15 Yamada Y, Hamajima N, Kato T, Iwata H, Yamamura Y, Shinoda M et al. Association of a polymorphism of the phospholipase D2 gene with the prevalence of colorectal cancer. J Mol Med 2003; 81: 126-131.

16 Zhao $Y$, Ehara $H$, Akao $Y$, Shamoto $M$, Nakagawa $Y$, Banno $Y$ et al. Increased activity and intranuclear expression of phospholipase D2 in human renal cancer. Biochem Biophys Res Commun 2000; 278: 140-143.

$17 \mathrm{Cho} J \mathrm{H}$, Hong SK, Kim EY, Park SY, Park CH, Kim JM et al. Overexpression of phospholipase D suppresses taxotere-induced cell death in stomach cancer cells. Biochim Biophys Acta 2008; 1783: 912-923. 
18 Riebeling C, Muller C, Geilen CC. Expression and regulation of phospholipase D isoenzymes in human melanoma cells and primary melanocytes. Melanoma Res 2003; 13: 555-562.

19 Chen Y, Zheng Y, Foster DA. Phospholipase D confers rapamycin resistance in human breast cancer cells. Oncogene 2003; 22: 3937-3942.

20 Noh DY, Ahn SJ, Lee RA, Park IA, Kim JH, Suh PG et al. Overexpression of phospholipase D1 in human breast cancer tissues. Cancer Lett 2000; 161: 207-214.

21 Sanematsu F, Nishikimi A, Watanabe M, Hongu T, Tanaka Y, Kanaho Y et al. Phosphatidic acid-dependent recruitment and function of the Rac activator DOCK1 during dorsal ruffle formation. J Biol Chem 2013; 288: 8092-8100.

22 Nishikimi A, Fukuhara H, Su W, Hongu T, Takasuga S, Mihara H et al. Sequential regulation of DOCK2 dynamics by two phospholipids during neutrophil chemotaxis. Science 2009; 324: 384-387.

23 Shi M, Zheng Y, Garcia A, Xu L, Foster DA. Phospholipase D provides a survival signal in human cancer cells with activated H-Ras or K-Ras. Cancer Lett 2007; 258 268-275.

24 Buchanan FG, McReynolds M, Couvillon A, Kam Y, Holla VR, Dubois RN et al. Requirement of phospholipase D1 activity in H-RasV12-induced transformation. Proc Natl Acad Sci USA 2005; 102: 1638-1642.

25 Min DS, Kwon TK, Park WS, Chang JS, Park SK, Ahn BH et al. Neoplastic transformation and tumorigenesis associated with overexpression of phospholipase $D$ isozymes in cultured murine fibroblasts. Carcinogenesis 2001; 22: 1641-1647.

26 Joseph T, Wooden R, Bryant A, Zhong M, Lu Z, Foster DA. Transformation of cells overexpressing a tyrosine kinase by phospholipase D1 and D2. Biochem Biophys Res Commun 2001; 289: 1019-1024.

27 Zhong M, Shen Y, Zheng Y, Joseph T, Jackson D, Foster DA. Phospholipase D prevents apoptosis in v-Src-transformed rat fibroblasts and MDA-MB-231 breast cancer cells. Biochem Biophys Res Commun 2003; 302: 615-619.

28 Foster DA, Xu L. Phospholipase D in cell proliferation and cancer. Mol Cancer Res 2003; 1: 789-800.

29 Henkels KM, Peng HJ, Frondorf K, Gomez-Cambronero J. A comprehensive mode that explains the regulation of phospholipase D2 activity by phosphorylationdephosphorylation. Mol Cell Biol 2010; 30: 2251-2263.

30 Gomez-Cambronero J. New concepts in phospholipase D signaling in inflammation and cancer. ScientificWorld J 2010; 10: 1356-1369.

31 Monovich L, Mugrage B, Quadros E, Toscano K, Tommasi R, LaVoie S et al. Optimization of halopemide for phospholipase D2 inhibition. Bioorg Med Chem Lett 2007; 17: 2310-2311.

32 Su W, Yeku O, Olepu S, Genna A, Park JS, Ren H et al. 5-Fluoro-2-indolyl deschlorohalopemide (FIPI), a phospholipase D pharmacological inhibitor that alters cell spreading and inhibits chemotaxis. Mol Pharmacol 2009; 75: 437-446.

33 Scott SA, Selvy PE, Buck JR, Cho HP, Criswell TL, Thomas AL et al. Design of isoform-selective phospholipase $D$ inhibitors that modulate cancer cell invasiveness. Nat Chem Biol 2009; 5: 108-117.

34 Price JE. Metastasis from human breast cancer cell lines. Breast Cancer Res Treat 1996; 39: 93-102.

35 Sossey-Alaoui K, Safina A, Li X, Vaughan MM, Hicks DG, Bakin AV et al. Downregulation of WAVE3, a metastasis promoter gene, inhibits invasion and metastasis of breast cancer cells. Am J Pathol 2007; 170: 2112-2121.

36 Stasinopoulos I, O'Brien DR, Wildes F, Glunde K, Bhujwalla ZM. Silencing of cyclooxygenase-2 inhibits metastasis and delays tumor onset of poorly differentiated metastatic breast cancer cells. Mol Cancer Res 2007; 5: 435-442.

37 Zheng Y, Rodrik V, Toschi A, Shi M, Hui L, Shen Y et al. Phospholipase D couples survival and migration signals in stress response of human cancer cells. J Biol Chem 2006; 281: 15862-15868.

38 Knoepp SM, Chahal MS, Xie Y, Zhang Z, Brauner DJ, Hallman MA et al. Effects of active and inactive phospholipase D2 on signal transduction, adhesion, migration, invasion, and metastasis in EL4 lymphoma cells. Mol Pharmacol 2008; 74: 574-584.

39 Chen Q, Hongu T, Sato T, Zhang Y, Ali W, Cavallo JA et al. Key roles for the lipid signaling enzyme phospholipase $\mathrm{d} 1$ in the tumor microenvironment during tumor angiogenesis and metastasis. Sci Signal 2012; 5: ra79.

40 You J, Mi D, Zhou X, Qiao L, Zhang H, Zhang X et al. A positive feedback between activated extracellularly regulated kinase and cyclooxygenase/lipoxygenase maintains proliferation and migration of breast cancer cells. Endocrinology 2009; 150: $1607-1617$.
41 Henkels KM, Farkaly T, Mahankali M, Segall JE, Gomez-Cambronero J. Cell invasion of highly metastatic MTLn3 cancer cells is dependent on phospholipase D2 (PLD2) and Janus kinase 3 (JAK3). J Mol Biol 2011; 408: 850-862.

42 Zeniou-Meyer M, Zabari N, Ashery U, Chasserot-Golaz S, Haeberle AM, Demais V et al. Phospholipase D1 production of phosphatidic acid at the plasma membrane promotes exocytosis of large dense-core granules at a late stage. $J$ Biol Chem 2007; 282: 21746-21757.

43 Frondorf K, Henkels KM, Frohman MA, Gomez-Cambronero J. Phosphatidic acid (PA) is a leukocyte chemoattractant that acts through $\mathrm{S} 6$ kinase signaling. J Biol Chem 2010; 285: 15837-15847.

44 Mahankali M, Peng HJ, Cox D, Gomez-Cambronero J. The mechanism of cell membrane ruffling relies on a phospholipase D2 (PLD2), Grb2 and Rac2 association. Cell Signal 2011; 23: 1291-1298.

45 Gomez-Cambronero J, Frye T, Baumann M. Ribosomal p70S6K basal activity increases upon induction of differentiation of myelomonocytic leukemic cell lines HL60, AML14 and MPD. Leuk Res 2004; 28: 755-762.

46 Henkels KM, Mahankali M, Gomez-Cambronero J. Increased cell growth due to a new lipase-GEF (Phospholipase D2) fastly acting on Ras. Cell Signal 2013; 25: 198-205.

47 Peng HJ, Henkels KM, Mahankali M, Marchal C, Bubulya P, Dinauer MC et al. The dual effect of Rac2 on phospholipase D2 regulation that explains both the onset and termination of chemotaxis. Mol Cell Biol 2011; 31: 2227-2240.

48 Peng HJ, Henkels KM, Mahankali M, Dinauer MC, Gomez-Cambronero J. Evidence for two CRIB domains in phospholipase D2 (PLD2) that the enzyme uses to specifically bind to the small GTPase Rac2. J Biol Chem 2011; 286: 16308-16320.

49 Zouwail S, Pettitt TR, Dove SK, Chibalina MV, Powner DJ, Haynes L et al. Phospholipase $\mathrm{D}$ activity is essential for actin localization and actin-based motility in Dictyostelium. Biochem J 2005; 389(Pt 1): 207-214.

50 Tsukahara T, Tsukahara R, Fujiwara Y, Yue J, Cheng Y, Guo H et al. Phospholipase D2-dependent inhibition of the nuclear hormone receptor PPARgamma by cyclic phosphatidic acid. Mol Cell 2010; 39: 421-432

51 Jiang H, Luo JQ, Urano T, Frankel P, Lu Z, Foster DA et al. Involvement of Ral GTPase in v-Src-induced phospholipase D activation. Nature 1995; 378: 409-412.

52 Jang JH, Lee CS, Hwang D, Ryu SH. Understanding of the roles of phospholipase D and phosphatidic acid through their binding partners. Prog Lipid Res 2012; 51: 71-81.

53 Itoh T, Hasegawa J, Tsujita K, Kanaho Y, Takenawa T. The tyrosine kinase Fer is a downstream target of the PLD-PA pathway that regulates cell migration. Sci Signal 2009; 2 ra52.

54 Gomez-Cambronero J. Biochemical and cellular implications of a dual lipase-GEF function of phospholipase D2 (PLD2). J Leukoc Biol 2012; 92: 461-467.

55 Shen Y, Zheng Y, Foster DA. Phospholipase D2 stimulates cell protrusion in v-Srctransformed cells. Biochem Biophys Res Commun 2002; 293: 201-206.

56 Su W, Chen Q, Frohman MA. Targeting phospholipase D with small-molecule inhibitors as a potential therapeutic approach for cancer metastasis. Future Oncol 2009; 5: 1477-1486.

57 Nielsen SE, Young JF, Daneshvar B, Lauridsen ST, Knuthsen P, Sandstrom B et al. Effect of parsley (Petroselinum crispum) intake on urinary apigenin excretion, blood antioxidant enzymes and biomarkers for oxidative stress in human subjects. Br J Nutr 1999; 81: 447-455.

58 Neiman AM. Prospore membrane formation defines a developmentally regulated branch of the secretory pathway in yeast. J Cell Biol 1998; 140: 29-37.

59 Neiman AM, Katz L, Brennwald PJ. Identification of domains required for developmentally regulated SNARE function in Saccharomyces cerevisiae. Genetics 2000; 155: 1643-1655.

60 Nakanishi $\mathrm{H}$, de los Santos P, Neiman AM. Positive and negative regulation of a SNARE protein by control of intracellular localization. Mol Biol Cell 2004; 15: 1802-1815.

61 Weimbs T, Low SH, Chapin SJ, Mostov KE, Bucher P, Hofmann K. A conserved domain is present in different families of vesicular fusion proteins: a new superfamily. Proc Natl Acad Sci USA 1997; 94: 3046-3051.

This work is licensed under a Creative Commons Attribution 3.0 creativecommonsorg/licenses/by/3.0/ 